Botchorishvili R. ${ }^{1}$, Wattiez A. ${ }^{2}$, Canis M. ${ }^{2}$, Rabischong B. ', Jardon K. ', Pouly J.L. ', Mage G.'

' Department of Obstetrics and Gynecology, Polyclinique de L'Hotel-Dieu, BD Leon Malfieyt, 63058 Clermont-Ferrand, France.

Department of Obstetrics and Gynecology, C.H.U. Hautepierre, 67098 Strasbourg, France

Introduction: Avoiding laparotomy by performing laparoscopic hysterectomy, of various types, has been shown to be beneficial in a number of ways. Shorter recovery times, shorter length of hospital stay and convalescence period, and earlier return to work than after abdominal hysterectomy are some of the positive factors cited. However, it is often considered that there is a size limitation of 14-16 weeks' gestation to the feasibility of laparoscopic hysterectomy. Whilst a number

\section{TOTAL LAPAROSCOPIC HYSTERECTOMY IN THE GROSSLY ENLARGED UTERUS}

of studies have shown that the laparoscopic-assisted vaginal hysterectomy (LAVH) successfully manages the large uterus, little has been published regarding a total laparoscopic approach.

Objective. To examine the practice and feasibil-ity of total laparoscopic hysterectomy (TLH) for uteri weighing $500 \mathrm{~g}$ or more compared to other total laparoscopic hysterectomies performed for the management of benign gynecological diseases. 
Patients: All patients who underwent total laparoscopic hysterectomy during the period January 2000 to December 2003 were included. Inclusion criteria included all women with benign uterine conditions. Malignant pathologies were excluded from the assess- ment. Patients who had pelvic floor prolapse treated laparoscopically concurrently with laparoscopic hysterectomy were also excluded. Sixty-nine patients with uterus $>500 \mathrm{~g}$ were compared to 537 patients with uterus $<500$ g.

\begin{tabular}{|l|c|c|}
\hline Characteristics & $\begin{array}{c}\text { Uterus }>\mathbf{5 0 0 g} \\
\mathbf{N}=\mathbf{6 9}\end{array}$ & $\begin{array}{c}\text { Uterus }<\mathbf{5 0 0 g} \\
\mathbf{N}=\mathbf{5 3 7}\end{array}$ \\
\hline Mean age & $47.1 \pm 4.7$ & $48.6 \pm 6.7^{*}$ \\
\hline$\%$ C/S & $10.1 \%$ & $14.1 \%$ \\
\hline Prior surgery & $17.4 \%$ & $25.1 \%$ \\
\hline - Laparoscopic surgery & 22.6 & 29.7 \\
\hline - Pelvic surgery & $1.5 \%$ & $6.0^{\circ}$ \\
\hline Endometriosis & 25.0 & $23.7^{\circ}$ \\
\hline Mean BMI & $13.0 \%$ & $20.3 \%^{\circ}$ \\
\hline Post-menopausal & $60.9 \%$ & $29 . \%^{\circ}$ \\
\hline Preoperative analogues & $677.9(500-1500)$ & $200.5(11-498)^{\circ}$ \\
\hline Mean uterine weight & & \multicolumn{2}{|c|}{} \\
\hline
\end{tabular}

Intervention. Total laparoscopic hysterectomy by the technic of Clermont-Ferrand.

Results. Patients with enlarged uteri had higher operating times and conversion rates, similar haemo-

globin levels pre and post operatively, similar hospital stays, and lower complications rates compared to patients with non-enlarged uteri.

Procedures
\begin{tabular}{|l|c|c|}
\hline TLH & Uterus $>\mathbf{5 0 0} \mathbf{g}$ & Uterus $<\mathbf{5 0 0 g}$ \\
\hline+ - USO/BSO & $88.4 \%$ & $97.2 \%$ \\
\hline - Adhesiolysis & $20.3 \%$ & $20.9 \%$ \\
\hline - Other procedure & $26.1 \%$ & $29.8 \%$ \\
\hline Mean hospital stay (days) & 3.67 & 3.65 \\
\hline Mean surgical time (min) & $135.8(60-280)$ & $106.4(40-330)^{\circ}$ \\
\hline
\end{tabular}

\section{Conversion}

\begin{tabular}{|l|c|c|}
\hline Reason for conversion & $\mathbf{> 5 0 0 \mathbf { g }}$ & $<\mathbf{5 0 0}$ \\
\hline Excessive hemorrhage & 0 & 2 \\
\hline Anaesthetic problems & 1 & 1 \\
\hline Emphysema & 0 & 0 \\
\hline Urinary tract injury & 0 & 1 \\
\hline Bowel injury & 2 & 0 \\
\hline Access/exposure & 6 & 13 \\
\hline Conversions to laparotomy & 6 & 7 \\
\hline Converted to LAVH \& laparotomy & 0 & 1 \\
\hline Converted to LAVH only & 3 & 9 \\
\hline TLH (type 4) & $87.0 \%$ & $96 . \%^{\circ}$ \\
\hline
\end{tabular}

Conclusion. A laparoscopic approach, by LAVH and TLH, is both feasible and beneficial in patients with enlarged uteri. The higher rate conversion may be as a result of cautiousness and extra vigilance with an operative case known to be of a greater degree of difficulty. Thus increased care with toilette and haemostasis may account for the lesser degree of complications in the group with enlarged uteri, particularly with regards to vault haematomas and infection. Most complications can be managed intraoperatively without reverting to laparotomy.

Total laparoscopic hysterectomy results in several advantages to patient - decreased hospital stay, and decreased convalescence. The longer learning curve is acknowledged. Once acquired, however, it can be seen from the data that it is safe and has low complication rates that are comparable to traditional laparotomic and vaginal approaches. 